\title{
Permanence of Publications and Records
}

$\mathrm{I}^{\mathrm{T}}$ is appropriate that a body such as the International Institute of Intellectual Co-operation of the League of Nations should make a matter such as the permanence of records one of its concerns, and a report (prepared by Mr. E. Whalley) has recently been published. It is of interest not so much as a record of experimental work, but as a statement of the attitudes of the countries concerned, for it consists mainly of the replies to a questionnaire asking for information on the state of preservation of publications and records and on the most desirable methods of preservation.

The preservation of certain printed and written documents is of importance, however small the country concerned, but it appears that in many instances, such as in Austria, Bulgaria, Cuba, Denmark, Holland, Italy and Luxembourg, many of the records belonging to the War and post-War periods are printed or written with materials which will not last. Presumably this state of affairs is due mainly to the War, but it may also be accounted for, to some extent, by the interval which has elapsed between the partial replacement of rags by esparto or wood pulp and the accumulation of scientific evidence as to the dependence of stability on the materials used and on the method of preparation.

The most useful contributions come from Great Britain and the United States, since actual specifications are given, and in the former case the views of several Government departments are expressed separately. Thus, the Public Record Office notes that the decade 1890-1900 may be regarded as the danger-period, so far as instability of paper is concerned, while the Stationery Office contributes its various specifications, which incidentally demand an all-rag composition with a minimum of added nonfibrous constituents. It appears that the British Museum takes no special precautions other than the exclusion of moisture for the preservation of printed books, although manuscripts are, in addition, protected against dust. The use of papers of special quality for copies of publications to be deposited at the Museum under the Copyright Act is commended. A general report was also received from the Government Chemist.

The subject has received considerable attention in official quarters in the United States, and as the conclusions reached are based on organised experimental work they are of great interest ; this is particularly the case since resistance to discoloration figures in the report. This factor, which has been somewhat disregarded in the past, is important not so much because the discoloration itself is objectionable as because a paper which discolours relatively rapidly in sunlight will deteriorate rapidly on storage. This is not surprising, since the discoloration of white papers is almost certainly related to degradation of the cellulose by chemical impurities. At the same time it is unwise to place too much trust on a high content of $\alpha$-cellulose as a guarantee of permanence, since the investigations of W. V. Torrey and E. Sutermeister ${ }^{1}$ on a number of papers up to 900 years old demonstrate that there is no connexion between the two; it is now being gradually appreciated that the chemical purity of the paper as a whole is of more importance than that of the fibrous portion only.

No less important than paper for the preservation of the written word is ink. It seems generally agreed in all quarters that carbon black is the most desirable ingredient, and a recommendation comes from Germany to the effect that the use of blue and violet typewriter ribbons for permanent records should be prohibited. The work of Holweck in Norway has enabled a specification to be compiled for ink, and a mobile, quick-drying, non-fading iron and tannin black ink, which is free from acidity and resistant to light, water or alcohol is preferred.

The recommendations of the Committee should serve as a valuable guide to those responsible for the selection of paper. Paper of appropriate chemical purity made from unbleached rags is still preferred; and iron tannate inks, and carbon papers and typewriter ribbons prepared from carbon black, are considered to be the least destructive of those available. At the same time it is appreciated that these are not ideal, and there appears to be scope for further work on the subject of inks. The publication of special limited editions of newspapers on a rag paper is to be encouraged, and all documents should be bound as soon as possible.

An important recommendation refers to conditions of storage. Extremes of temperature, humidity and light are the most potent accelerators of deterioration, but dust, insects and bad binding also play a part. In this connexion it is understood that humidity and temperature control has been installed at the Archives Building at Washington, D.C. Permanent displays of documents are undoubtedly responsible for hastening deterioration and are therefore undesirable. The chemical purity of the air is also worth consideration since A. E. Kimberly ${ }^{2}$ and others have recently shown that books from libraries in towns deteriorate more rapidly than those from country libraries, presumably owing to the higher sulphur dioxide content of the air in the former case.

Finally, the committee decided that a bulletin should be issued from time to time as a means of directing attention to recent developments in science which have a bearing on the above matters.

This article would be incomplete without reference to a report of the Technical Association of the American Pulp and Paper Industry which has just appeared ${ }^{3}$. In addition to discussions of the individual effects on stability of the various fibrous and non-fibrous constituents of paper, this attacks the difficult problem of accelerated ageing tests. These tests usually involve a determination of the change in certain physical tests (for example, resistance to folding) after heat-treatment under specified conditions. Unfortunately it is impossible to test the value of such tests other than by exposure for many years, but the opinion is expressed that they are of questionable value for inclusion in specifications. In the meantime, therefore, the only reliable alternative is to select a paper similar to those which have already stood the test of time, and it seems that until the passage of time provides us with more information concerning the behaviour of wood and esparto pulps, unbleached cotton, hemp or flax fibres will continue to hold the field as the basis of durable papers.

J. G.

${ }_{2}$ Paper Trade J., Tech. Sec., 96, 267 ; 1933.

2 Bur. Stand. Misc. Publ., Nos. 128 and 140; 1933.

3 Paper. Trade J., Tech. Sec., 97, 37 ; 1933. 